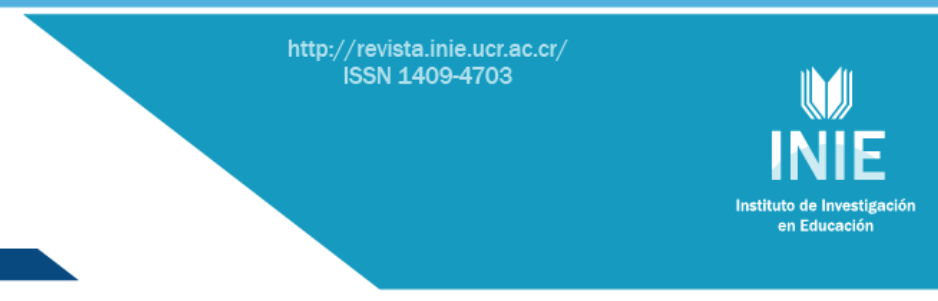

\title{
INNOVACION CURRICULAR EN TURISMO: UN CAMPO DE ESTUDIO Y REFERENTES PARA LA FORMACIÓN UNIVERSITARIA
}

CURRICULUM INNOVATION IN TOURISM: A FIELD OF STUDY AND REFERENCES FOR UNIVERSITY TRAINING

\author{
Volumen 13, Número 1 \\ Enero - Abril \\ pp. 1-39
}

Este número se publicó el 30 de enero de 2013

Lucía M. Collado Medina

Lourdes Medina Cuevas

Alma Herrera Márquez

Maricruz Moreno Zagal

Revista indizada en REDALYC, SCIELO

Revista distribuida en las bases de datos:

CATÁLOGO DE LATINDEX, IRESIE, CLASE, DIALNET, DOAJ, E-REVIST@S, SHERPA/ROMEO, QUALIS

Revista registrada en los directorios:

ULRICH'S, REDIE, RINACE, OEI, MAESTROTECA, PREAL, CLASCO 


\title{
INNOVACION CURRICULAR EN TURISMO: UN CAMPO DE ESTUDIO Y REFERENTES PARA LA FORMACIÓN UNIVERSITARIA CURRICULUM INNOVATION IN TOURISM: A FIELD OF STUDY AND REFERENCES FOR UNIVERSITY TRAINING
}

\author{
Lucía M. Collado Medina ${ }^{1}$ \\ Lourdes Medina Cuevas ${ }^{2}$ \\ Alma Herrera Márquez ${ }^{3}$ \\ Maricruz Moreno Zagal ${ }^{4}$
}

\begin{abstract}
Resumen: El artículo presenta un panorama de la investigación curricular en turismo reportada en México y otros países, principalmente latinoamericanos. Se definen tendencias, impactos, alcances, pautas de problemáticas emergentes, y referentes para aclarar enfoques y modelos de la formación profesional e innovación curricular de este campo. Con base en el método de mapeo se seleccionaron y valoraron las fuentes que sustentan este estudio, mediante las cuales se plantean los retos para la construcción de modelos curriculares innovadores. Se vislumbran nuevos paradigmas inter y transdisciplinarios para abordar curricularmente el caso del turismo. Con respecto a lo anterior, se concluye tomar en cuenta supuestos epistemológicos congruentes con la complejidad y la incertidumbre que subyacen a los modelos de formación en turismo, pertinentes al entorno social y humano.
\end{abstract}

Palabras clave: CURRÍCULUM, INNOVACIÓN CURRICULAR, FORMACIÓN EN TURISMO, MEXICO

\begin{abstract}
This article presents an overview of curriculum research in tourism reported in Mexico and other countries, mainly in Latin America. It defines trends, impacts, scope, patterns of emerging problems, and referents to clarify approaches and models of professional development and curriculum innovation in this field. Based on the mapping method, the sources underpinning this study were selected and evaluated. These sources pose challenges for modeling innovative curriculum. New paradigms are emerging to address inter-and transdisciplinary the case of the tourism curriculum. With regard to the above, we conclude consider epistemological assumptions consistent with the complexity and uncertainty underlying models of tourism training, relevant to social and human environment.
\end{abstract}

Keywords: CURRICULUM, CURRICULUM INNOVATION, TOURISM TRAINING, MEXICO

\footnotetext{
${ }^{1}$ Maestra en Estudios Turísticos, Docente e Investigadora del Centro de Investigación y Estudios Turísticos de Universidad Autónoma del Estado de México. Dirección electrónica: lucymcm8891@gmail.com

2 Doctora en Educación, Docente Investigadora del Centro de Investigación y Estudios Turísticos de la Universidad Autónoma del Estado de México. Dirección electrónica: lumec57@yahoo.com.mx

3 Doctora en Pedagogía, Docente FES Zaragoza de la UNAM. Coordinadora Cátedra UNESCO: Universidad e Integración Regional. Miembro del Sistema Nacional de Investigadores, México. Dirección electrónica: alserro57@gmail.com

4 Doctora en Pedagogía, Profesora investigadora de la Universidad Autónoma del Estado de México. Dirección electrónica: maryzagal@hotmail.com
}

Artículo recibido: 21 de noviembre, 2011

Aprobado: 22 de noviembre, 2012 


\section{Introducción}

El currículum se ha constituido en un campo de conocimiento ${ }^{5}$ que abarca múltiples dimensiones de la práctica educativa. La vasta producción de investigaciones refieren tendencias en su concepción, diseño, instrumentación, aplicación y evaluación, sustentadas en el análisis de los cambios contextuales y paradigmáticos del pensamiento humano, que ayudan a comprender los fines de la formación profesional, su evolución y la transición hacia nuevos discursos y modelos para insertarse a un nuevo orden universal determinado por la incertidumbre y la complejidad.

Como campo de conocimiento, convoca a pensar y discutir sobre los elementos que constituyen la praxis educativa, a descubrir las teorías implícitas en la práctica cotidiana en la que muy pocas veces se reflexiona a profundidad, individual o colectivamente y la que probablemente encierra una riqueza de experiencias que bien pueden traducirse en conocimiento explícito, pleno de elementos y teorías que argumenten un cambio profundo.

En este sentido, es pertinente crear espacios libres y democráticos que favorezcan la deliberación en torno a las ideologías, creencias, percepciones, experiencias y conocimientos, que se constituyan en la base de la discusión curricular y propicien un conjunto de relaciones y acciones complejas, para reconstruir con sentido y pertinencia, modelos innovadores en la formación profesional en turismo, desde una perspectiva participativa.

La innovación como un acto que conlleva implicaciones epistemológicas, sociales y políticas apunta a transformar los paradigmas de pensamiento y acción en torno a la formación profesional en turismo; desencadenar procesos para reformar las funciones, propósitos, contenidos, escenarios, métodos y producir nuevos modelos que a su vez propicien sinergias entre formas diferentes de comprender y actuar en el mundo. Se parte de la configuración de redes abiertas y flexibles para la intervención multidimensional del objeto de aprendizaje del turismo; definir ejes de construcción curricular que articulen conocimiento, comprensión y método; rebasar el concepto de innovación técnica y posicionar al sujeto en su práctica cotidiana desde una perspectiva crítica para dilucidar sobre las

5 La noción de campo es una categoría organizativa del conocimiento. El campo es una fuente de teoría e investigación. El campo instituye la división y especialización del trabajo y articula las disciplinas y regiones que abarca la ciencia. El campo de reproducción constituye una estructura organizativa para la reproducción selectiva de discursos educativos (Bernstein, citado por Magendzo, 2006). 
complejidades e incertidumbres que constituyen su entorno de actuación asumiendo que su mediación en la construcción curricular supone procesos de aprendizaje en los que intervienen "la realidad, la subjetividad, el lenguaje, las comunicaciones sociales" (Pérez, 2007), así como otros factores fundamentales como el conocimiento, la experiencia y la relación social.

En la investigación curricular, el concepto de red se puede aplicar a la producción y gestión del conocimiento como factor de innovaciones que trasciendan del plano funcional o tecnocrático al plano filosófico y epistemológico. Como procesos que se sustentan en las relaciones e interacciones sociales, que contienen potencial a través de la tecnología, pero que en su desarrollo derivan aspectos relevantes como la vinculación, las relaciones, la gestión, la colaboración, los intereses, las intensiones y motivaciones comunes, la evaluación, el replanteamiento conceptual y estratégico.

El artículo aproxima fundamentos para la construcción de una plataforma epistémica que permita centrar una concepción teórica y metodológica para estudiar la formación en turismo desde una perspectiva inter y transdisciplinar, de tal forma que aporte elementos explicativos y pautas estratégicas en la configuración de modelos innovadores, partiendo de identificar los avances y aportaciones en la conformación y gestión del conocimiento curricular en la educación superior universitaria y sus derivaciones en la innovación curricular en turismo.

La investigación se desarrolló usando el método de mapeo sugerido por Creswel (2005), para analizar y reflexionar sobre experiencias de investigación educativa, particularmente contenidas en estados de conocimiento o estudios referidos al currículum en educación superior y específicamente a la formación universitaria en turismo, desarrollando un mapa de referencias o "literature map" (Creswell, 2009, p. 33).

El método consiste en explorar, organizar y realizar una valoración crítica de estudios relacionados con el tema de la investigación a fin de dar el soporte a los argumentos que se sostienen; construir un esquema conceptual para jerarquizar e interconectar la información, teniendo como eje el propósito de la investigación. A partir de este esquema conceptual, se debate sobre los elementos teóricos y epistemológicos que sustentan en este caso, los procesos de construcción y desarrollo curricular.

Para observar la configuración de este campo de estudio, se parte de identificar las líneas de investigación del campo curricular en general, para luego examinar ejes de análisis 
sobre el currículum en turismo, sus retos y perspectivas de innovación, distinguiendo tramas emergentes para aprehender nuevas formas de interpretar la realidad, aplicar el conocimiento, liberar el potencial creativo y transformador de las prácticas educativas, que en función del entorno problemático surgen en sus ámbitos de aplicación.

Se seleccionaron y analizaron los trabajos que reconocen la producción de conocimiento curricular en la educación superior, como fuente que sustenta sub-campos en niveles educativos específicos, como es el caso del currículum universitario relacionado con la formación profesional en turismo.

A través de estudios realizados sobre la formación en turismo, donde se identifican las principales tendencias, temáticas, ejes problemáticos, impactos y alcances logrados, se visualiza un cambio paradigmático en la construcción de los modelos curriculares. Este acercamiento ha dado pauta a la definición de los retos y perspectivas para construir propuestas curriculares innovadoras basadas en prácticas participativas, que permiten comprender y reformular los procesos educativos desde su concepción hasta su evaluación.

Se concluye con algunas reflexiones acerca del carácter multidimensional y multidisciplinar del turismo como objeto de estudio que demanda la asunción de nuevos enfoques epistemológicos para diseñar propuestas curriculares con pertinencia social en su determinación conceptual y contextual.

\section{El campo de conocimiento curricular. Desarrollo e innovación}

De acuerdo con G. De Landsheere (1996), la investigación educativa ha alcanzado niveles científicos que la equiparan con otras disciplinas, descubriendo diferencias profundas de desarrollo entre los ámbitos y las temáticas que aborda, y constituyendo un cuerpo de conocimientos que contribuye al diseño y el desarrollo de programas de formación. Uno de los campos de mayor desarrollo se focaliza en el currículum en sus diversas vertientes conceptuales, teóricas, metodológicas, epistemológicas, tendenciales y problémicas, considerando que es el eje fundamental de toda reforma, reestructuración o innovación educativa, caracterizado como un objeto de estudio dinámico que evoluciona históricamente y se define a partir de contextos específicos, ofreciendo múltiples posibilidades de investigación.

El origen del campo de investigación y conocimiento curricular se ubica en los primeros años del Siglo XX, cuando la industrialización origina los sistemas escolares masificados, a 
fin de asegurar el progreso económico a través de la especialización profesional y la aplicación de los principios del taylorismo en la educación desarrollados en países como los Estados Unidos, Inglaterra y Australia. Desde entonces, la teoría curricular contiene las aportaciones de autores como Bobbit (1918), Tyler (1949), Taba (1962, 1974), Gagné (1967), Stenhouse (1975, 1981), Young (1971), Huebner (1976, 1983), Kliebard (1977), Pinar (1979), Lawn y Barton (1980), Coll (1987), Zabalza (1987), Kemmis (1988), Sacristán (1988, 1991, 2008, 2010), Jackson (1992), Lundgren (1981, 1992), De Alba (1994), Grundy (1998), Da Silva (1999), Davini (1999), por mencionar solo algunos.

Hacia 1963 en Chicago se lleva a cabo una Conferencia sobre el Contenido del Currículum, en la que se discute la problemática de estancamiento, dando pauta al intervencionismo del Estado y la mediación de otros actores y disciplinas en la revisión de contenidos y métodos para desarrollar el conocimiento del estudiante, en las áreas de la ciencias básicas (matemáticas y ciencias naturales), a través de proyectos de innovación.

Así se ha configurado un campo de estudio, que particularmente en México tiene su fundamento en las ideas educativas hegemónicas de Norteamérica, centradas en la perspectiva de objetivos conductuales, proliferando en la educación superior universitaria en donde su autonomía respecto al sistema educativo, permite diseños con orientaciones pedagógicas y disciplinarias específicas.

Las nociones del currículum desarrolladas a lo largo del tiempo ofrecen alternativas de análisis en dos sentidos genéricos: las transformaciones culturales, sociales y políticas que lo han encauzado y los aspectos relacionados con el diseño, desarrollo e innovación curricular, situados en corrientes teóricas y epistemológicas diversas, que han coexistido entre posturas que, estudiosos del currículum como Kemmis (1988) y Grundy (1998), identifican a partir de intereses cognitivos centrados en los enfoques técnico, práctico y emancipatorio. Así lo confirman diversas investigaciones, que han conformado estados de conocimiento en el campo educativo en México y otros países latinoamericanos, a lo largo de las últimas dos décadas del Siglo XX, con trabajos que presentan un análisis de la extensa producción en investigación curricular y han permitido identificar los objetos de estudio y sus referentes conceptuales, los principales enfoques teórico-metodológicos, tendencias y temas, los problemas de investigación y los vacíos de conocimiento, su contexto socioeconómico y político, tensiones e impactos. 
Los estudios realizados suscriben elementos para pensar nuevas rutas de análisis y construcción curricular; son de carácter analítico, crítico, histórico y contextual que sistematizan y dan cuenta de sus orígenes, tendencias e impactos a nivel nacional o regional. En México, los aportes realizados por Díaz Barriga, A. (2003) y Díaz Barriga, F. (2005), en el nivel superior, traman su conceptualización, desarrollo, procesos y prácticas, así como en otros contextos, autores como Ferrer (1998 y 2004), Terigi (2002), Fabara y Hernández (2003) y Dussel (2006) dejan ver en los modelos y tendencias del currículum, núcleo fundamental de toda reforma, reestructuración o innovación educativa, su potencial de respuesta a las transformaciones de las sociedades humanas.

A partir de estas transformaciones, la educación superior que se imparte en la Universidad es motivo de cuestionamientos y debates relacionados con el impacto social que debería producir, como formadora de profesionales capaces de intervenir socialmente; producir conocimiento relevante desde distintas áreas de estudio y profesionalización; promover estrategias y medios para involucrar no solo a sus comunidades, sino a distintos grupos sociales en la producción, distribución, uso y aplicación del conocimiento enfocado al bienestar humano y asegurar, frente a los grandes desafíos que plantea la globalización y liberación de las economías, la esencia de la función formativa de la Universidad como el significado social y humano de la educación integral que trasciende del individuo a la sociedad y viceversa.

Investigar la evolución del currículum ha producido la integración de un campo de experiencias y conocimiento al que poco se acude desde el ámbito de las reformas educativas, ya que al parecer, salvo en algunas excepciones (véase Braslavsky y Cosse, 2006), es de poca utilidad frente a los grandes intereses que dominan la economía y la política, pero ciertamente se rescata a nivel de rediseño e innovación en la práctica. El trabajo realizado hasta el momento representa un gran esfuerzo de sistematización del conocimiento acumulado de este objeto de estudio, cuyos orígenes se piensa, datan desde la época clásica (Siglo XVII) cuando el ser humano comenzó a determinar qué conocimiento conduciría su propia evolución (trívium y cuadrivium), a partir de su necesidad de comprensión del mundo.

De modo que el resultado de este análisis cumple con dos funciones: comprender la base conceptual de los modelos curriculares altamente deterministas y dilucidar sobre el marco valorativo de la intersubjetividad y la interdisciplinariedad como conocimiento que 
subyace a la construcción y desarrollo complejo del currículum, lo que influye en un tratamiento de base epistémica.

El estado de conocimiento coordinado por Díaz Barriga (2003), considerado entre los más amplios y completos de América Latina, se mencionan diversos estudios realizados en la décadas de los 90 que analizan los aspectos teóricos y empíricos del currículum, su evolución histórica y conceptual, las perspectivas psicológica y sociológica, cuantitativa y cualitativa, la determinación de los contenidos, los temas y los paradigmas emergentes en torno al humanismo, la cultura y el ambiente, delineándolo como un campo de conocimiento de múltiples objetos y procesos de gran complejidad, con posibilidades de abordaje multi, inter y transdisciplinar.

Las primeras reflexiones que plantea el autor, giran en torno a cuestionar qué es el currículum y cómo es que se reafirma su carácter prescriptivo, para conducirnos a comprender que el contenido curricular no son los temas seleccionados para desarrollar la enseñanza, los métodos y los materiales, sino también, los principios ideológicos, epistemológicos, teóricos y metodológicos que subyacen al conjunto de modelos educativos y de prácticas de diseño y desarrollo que se van articulando y que, a partir de un ejercicio crítico y reflexivo permanente, sería posible reorientar.

Así, uno de los ámbitos o temas que se investiga es su conceptualización. La evolución del currículum se fundamenta y al mismo tiempo produce diversos enfoques que parten de principios teóricos de las áreas de la psicología y la sociología (conductuales, cognitivos, constructivistas; positivistas, interpretativos o críticos respectivamente) o de paradigmas dominantes como la teoría educativa liberal; el paradigma economicista (capital humano, recursos humanos) y el paradigma crítico-reproductivista (Tedesco, 1986), que han fundamentado diversidad de modelos marcando el horizonte curricular, donde todavía prevalecen ejercicios caracterizados por la simplificación de las problemáticas socioeducativas, introduciendo altos niveles de homogeneidad en las variables curriculares (conceptos, valores, métodos, estrategias, medios, actividades, evaluación), ignorando puntos de ruptura, tendencias de transformación y oportunidades para mejorar los procesos.

Más allá de cualquier sustento teórico, el currículum también puede interpretarse según la función política que se le atribuya: como un espacio de conflicto (Díaz Barriga, A., 1988), donde se lucha por sostener posturas ideológicas en cuanto a lo que es o lo que debe ser, una herramienta de la política educativa o de trabajo de los equipos docentes (Terigi, 2002), 
un foco intelectual y organizativo de los procesos educativos (Díaz Barriga A., 2003) o un espacio de debate y definición de fines, contenidos, procesos y disputas por el poder (Díaz Barriga F. y Lugo, 2003), que se desarrolla en entornos definidos para crear modelos y propuestas específicos.

El trabajo elaborado por Díaz Barriga, F. y Lugo, E. (2003) evidencia esta diversidad de concepciones relacionando más del $50 \%$ de la producción investigativa con el desarrollo de modelos y propuestas educativas, el $80 \%$ de ellas en el nivel superior, lo que lleva a suponer que el currículum se determina, más bien, en contextos de dominio y aplicación para construir consensos y transformar los contenidos académicos, además, de decidir las intensiones formativas y los fines educativos. Las autoras afirman que el significado del currículum no puede reducirse a sus connotaciones literales e institucionales, sino que es un concepto altamente simbólico.

Stenhouse (1991, p. 29) lo definió como "una tentativa para comunicar los principios y rasgos de un propósito educativo, de forma tal que permanezca abierto a discusión crítica y pueda ser trasladado efectivamente a la práctica". Sin embargo, comúnmente la discusión crítica del currículum es un asunto poco prolífico que deciden casi en exclusiva los "expertos", pero la discusión profunda, sistemática, crítica y legítima es una tarea pendiente en la que todos los actores tienen una participación fundamental.

Los estudios de la evolución histórica, conceptual y social del currículum señalan los cambios paradigmáticos que marcan en cada etapa, el agotamiento de las perspectivas con las que se ha construido el currículum, pero no es solo eso, sino que también revelan la visión del ser humano y la sociedad, que en esta época ha llegado a un estado de incertidumbre casi radical y a un nivel de complejidad que estimula la confrontación de las posturas que se asumirán desde el currículum, para construir una nueva visión del mundo.

La investigación curricular confirma un conjunto viejos supuestos comprensivos sobre la relación sociedad-educación, donde existe una implicancia mutua en la misión de formar integralmente ciudadanos que correspondan a la aspiración de una sociedad más justa y equitativa; es así como en países latinos se señalan supuestos similares, aunque contextualmente se interpretan y responden a causas y necesidades sociopolíticas y económicas distintas, como en el caso de Perú, Chile, Colombia y Argentina (Ferrer 1998, 2004; Dussel, 2006; Terigi, 2002; Fabara y Hernández, 2003), donde el discurso dicta que la educación debe ser tributaria de sociedades libres, justas y democráticas para que las 
oportunidades sean para todos. Las posturas críticas han calificado al currículum como instrumento de reproducción hegemónica y de sistemas educativos excluyentes que en el mejor de los escenarios ofrece fecundas herramientas para la acción, no así para el pensamiento.

Desde el paradigma liberal de mediados del siglo XX, la contribución de la educación a la formación social se encaminó a la preservación de un orden político democrático y liberal con valores asentados en la ciencia positivista para descubrir el cómo llegar a esos propósitos creando métodos didácticos conductistas, que posteriormente producen reacciones en contra, surgiendo la llamada "Escuela Nueva", cuyos principios metodológicos otorgaban mayor libertad a los procesos pedagógicos centrados en observar la realidad desde la escuela.

De este modo, nace el debate entre las concepciones de la llamada "pedagogía tradicional" y la "pedagogía nueva", aunque ninguna de ellas formuló respuestas a la industrialización y expansión económica posterior a la Segunda Guerra Mundial. En este sentido, los postulados del liberalismo educativo quedaron plasmados solo en el discurso y fueron sustituidos por tendencias economicistas orientadas a formar recursos humanos con enfoques de planificación, para el desarrollo del capital humano que fortalecería la productividad como el principal requerimiento social.

A partir de la década de los 70 , al registrarse una recesión económica mundial, este paradigma empezó a cuestionarse ante nuevas miradas críticas que discutían el carácter reproductivista de la educación, aún vigente en el nuevo siglo, que dio origen a la masificación de la educación para el empleo cuya oferta hoy es rebasada por la capacidad del sistema económico para dar cobertura a las necesidades de empleo. Tedesco (1986), afirma que el reproductivismo agota su capacidad explicativa frente a los cambios que se vislumbran en las sociedades capitalistas avanzadas, a partir de las transformaciones científico-técnicas y su impacto en la división del trabajo. Durante esta década, y a mediados de los 80 , se comenzaron a considerar otro tipo de variables sociales que generaron diversidad de metodologías en el diseño, desarrollo y evaluación curricular, surgiendo como una tendencia que marca la década de los 80 , la incorporación de categorías sociológicas (poder, cultura y valores) y las aportaciones de pensadores como Bourdieu, Foucault (citados por Barrón, 2010) que dan cuenta de los procesos político-pedagógicos de la producción del conocimiento y de la reproducción del sistema cultural. 
El itinerario de transformaciones y rupturas paradigmáticas liberales y críticas en el mundo occidental, ha tratado de seguir la misma trayectoria en América Latina, sin embargo las condiciones políticas, sociales y económicas han creado situaciones peculiares ya que mientras en los Estados Unidos y Europa existen esquemas nacionales consolidados, muchos países de esta región se encuentran aún en el proceso, con problemas de atraso social y dependencia política y económica. La entrada tardía al sistema capitalista obligó a países como México a adaptarse a los avances científicos y tecnológicos, con marcadas desventajas en lo educativo que aún se reflejan en un entorno de crisis estructural, ideológica y de valores.

En el tema del desarrollo del currículum, con mayor producción en investigaciones y propuestas, se han identificado las principales tendencias y modelos desde los cuales se reorientó el diseño y operación de los proyectos curriculares en la década de los 90, aún condicionados por la racionalidad técnico-instrumental, donde el conocimiento es más bien considerado un instrumento para llegar a los objetivos. Como un signo de progreso, se definió que la noción de desarrollo (Gimeno, 1988) debe abarcar la actividad de diseño de modelos o propuestas curriculares, así como la diversidad de procesos y acciones que tienen lugar en contextos educativos y culturas concretas, donde se realizan las prácticas educativas desde la planeación, la selección y la organización de contenidos curriculares hasta la generación y puesta en marcha de propuestas innovadoras para la elaboración de planes y programas. Este sentido determina que el desarrollo curricular no es solo un programa predefinido con una temporalidad y un discurso teórico, sino un proceso, y como tal, implica pensamiento y acción.

Los planes y programas de estudio, que ofrecían un desglose de temas para aprender conocimientos teóricos y desarrollarse en contextos estructurados, están siendo lentamente reemplazados por propuestas que contemplan la necesidad de educar individuos para una sociedad desestructurada y compleja. Los modelos de organización de contenidos surgidos en los últimos años de la década del 90 en América Latina, como el currículum por competencias, el modelo por bloques o ejes temáticos, por expectativas de logro (competencias complejas), por objetivos específicos o indicadores de logro sin referencia a saberes conceptuales o procedimentales específicos (Ferrer, 1998), vienen marcando la pauta para los cambios que exige la entrada al nuevo milenio. 
Díaz Barriga F. y Lugo (2003) identificaron modelos innovadores surgidos en México, como el diseño por competencias, la flexibilidad curricular, el currículum centrado en el alumno, la formación en la práctica y experiencial, la formación por temas o ejes transversales y la incorporación de modelos basados en las TIC, los cuales han tenido implicaciones pedagógicas y metodologías intentando recuperar espacios para la reflexión, la innovación y el trabajo colaborativo con base en la gran producción de conocimiento que trata de orientar el desarrollo curricular desde los enfoques teóricos emergentes, que solo se manifiesta en el diseño, pero no en el campo de la práctica, al menos de modo significativo.

Se han propuesto modelos curriculares con distintos bagajes conceptuales (globalizado, intercultural, integrado) que tratan de compensar las limitaciones que han producido los modelos tradicionalistas y rígidos que, aunque han sido sujetos de innovaciones, estas son reproducidas sobre la base de las estructuras dadas, causando un bajo impacto al privilegiar unos aspectos y obviar otros, limitando las expectativas de cambio significativo que en esencia proviene de las esferas subjetiva e intersubjetiva.

Un avance hacia esta perspectiva lo trabaja Torres (2003), cuando identifica procesos y prácticas educativas, que desde el ámbito académico y áulico emergen con enfoques curriculares posmodernos en los que se habla de multiculturalidad, género, racismo e identidades. Analiza autores que han desarrollado estas perspectivas (Pinar, 1999; Da Silva, 1999; Díaz Barriga A., 2003) con estudios interpretativos centrados en la visión de los sujetos en el currículum, en la diversidad de procesos afectivos, cognitivos, ideológicos, intersubjetivos, de interacción que ocurren en el aula o en la institución educativa, y se estudian para conocer y comprender el microcampo curricular desde el paradigma cualitativo con metodologías como la etnografía, la investigación-acción, hermenéutica, estudio de casos, entre otras.

Este vertiente ha sido poco abordada por la complejidad que comporta; sin embargo, la autora afirma que el campo curricular en la perspectiva de las prácticas y los procesos, concuerda con las tendencias de currículum oculto, la sociología del conocimiento y la praxiología cuyos objetos abstractos como la reflexión, la cultura, la experiencia, la ideología, el poder, permiten un acercamiento a las formas de construcción institucional, de los sujetos y de los proyectos académicos para dar cuenta de ellos y recuperar lo propiamente cultural y social de los actos humanos; considera este, un ámbito de frontera, articulado con las prácticas educativas y, en consecuencia, con las prácticas curriculares. 
Pero ¿qué regula al currículum? Dussel (2006) afirma que el currículum se simboliza en las escuelas y debe atender a las intersubjetividades que involucran las formas de interacción de los actores, los factores mediadores y las relaciones internas, lo cual evidentemente le otorga el significado que marca la norma. En la actualidad, estos elementos simbólicos se van transformando al cambiar el rol de los actores, los dispositivos de mediación y la estructura de las relaciones que hoy también surgen fuera del aula y de la propia escuela, creando una visión epistemológica que se comprende poco, no se externaliza abiertamente en los discursos y en los textos se menciona simplemente como un contenido que aún no produce sentido.

En resumen, el diseño de nuevos modelos y propuestas curriculares, ha pasado de las visiones técnico-instrumentalistas a la planeación estratégica, a la lógica disciplinar y didáctica y, actualmente, a las de naturaleza cualitativa y hermenéutica que tratan de descubrir los valores y los principios epistemológicos con los que se construyen dichos modelos, superar la falta de coherencia y otorgar sentido de autenticidad, significado y pertinencia a los principios y los procesos.

La perspectiva de ámbito de frontera que plantea Torres (2003), abre la posibilidad de investigar el proceso de producción de conocimiento curricular, así como su dimensión de práctica social y educativa para develar el trasfondo ideológico de la intervención de los actores del currículum, promoviendo la ética y la crítica en el compromiso de colaborar para la mejora e innovación de la realidad educativa, reconociendo que las prácticas, individuales o colectivas, tienen una base teórica y epistemológica, cognoscitiva, ética y valorativa que no siempre se manifiesta en la dinámica anquilosada y hermética del diseño curricular y de las escuelas, que en muchas ocasiones avanzan a un ritmo discordante y con desconocimiento de lo ganado en el campo del conocimiento curricular.

Frente al horizonte de cambios y de crisis, la organización, la estructura de las prácticas educativas y curriculares no ha cambiado mucho. De acuerdo con lo investigado (Tedesco, 1986; Ferrer, 1998 y 2004; Terigi, 2002; Díaz Barriga A., 2003; Díaz Barriga F. y Lugo, 2003, Díaz Barriga F., 2005; Dussel, 2006), se ha demostrado la insuficiencia de los paradigmas surgidos en torno al desarrollo curricular y sobrevienen, con las transformaciones actuales, las rupturas epistemológicas y el replanteamiento del currículum.

Reflexiones planteadas por Grundy (1998), Morin (1999), Magendzo (2006), Gimeno (2008 y 2010) y Rogiers (2010), por citar algunos, indican que las nociones se orientan a 
interpretarlo como una práctica social reflexiva, que exige reconocer la diversidad de mediaciones que intervienen en sus procesos, con una dinámica compleja entre sus elementos, impactando en el desarrollo de nuevas perspectivas que produzcan conocimiento y sustenten los valores pertinentes al contexto actual. Shwab (1989), subrayó en su momento que la evolución del currículum ha sido teórica y ese sesgo ha tenido consecuencias en su implementación al imprimir un carácter técnico a la labor institucional de educar, tratando de llevar los principios y propósitos teóricos a la práctica, pero sin saber qué hacer con los constantes cambios que experimenta la realidad y que la teoría a priori, no es capaz de explicar.

El conocimiento es uno de esos valores al que se le ha dado una especial ponderación dentro de la economía, caracterizado como un bien que dio origen a la Sociedad del Conocimiento. Así lo precisó Drucker en 1969, al advertir la existencia de un sector emergente de la sociedad al que denominó trabajadores del conocimiento; Bell en 1973, quien al hablar de la sociedad post-industrial, señaló la transición hacia una economía basada en la producción de servicios, cuya materia prima es el conocimiento profesionalizado, marcando la preferencia por una clase social técnicamente cualificada y Castells que definió en 1997 la era de la información para describir un nuevo tipo de sociedad red que basa su desarrollo en las redes informáticas interactivas.

Es un concepto que ha evolucionado señalando una nueva etapa histórica en el desarrollo de la humanidad, encierra las transformaciones que ha experimentado y se manifiesta en los avances que se presumen para mejorar la calidad de vida en las sociedades más avanzadas, creando dimensiones polarizadas en el acceso, producción y gestión de la información y el conocimiento, que fomenta a la vez la desigualdad y la falta de equidad social ocasionando graves problemas de marginación.

Ante los nuevos escenarios delineados por la sociedad del conocimiento, la globalización y la interconexión, el campo del currículum requiere renovar principios y métodos que confronten viejos problemas con problemas emergentes, que impulsan nuevos modos de interactuar, como un cambio educativo necesario. Remite a un tipo de transformaciones profundas, que pueden afectar las estructuras en sus distintas dimensiones: cognitiva, pragmática, actitudinal, ética, política. Un concepto que se refiere a transformaciones cercanas y posibles es la innovación, que de un modo práctico afecta las dimensiones concretas del currículum: los procesos y las prácticas, aunque en el fondo 
comporta una concepción de las capacidades no solo del ser humano, sino de la sociedad, basadas en el conocimiento.

La innovación curricular ocurre en el contexto mismo de la situación educativa (tiempo y espacio) y se configura en la convergencia de conocimiento, afectividad, pensamiento y acción de los que intervienen y le otorgan sentido y significado, a partir de sus propias prácticas y de su cultura. Es en esencia, una manifestación de ruptura paradigmática mucho más evidente a pequeña escala, esto es, en las prácticas concretas donde nacen y se consolidan los propósitos y fines de innovar.

Díaz Barriga A. (1988) destaca que la expresión innovación curricular se ha trivializado, y apunta básicamente a los cambios técnicos en el plan de estudios, pero no a la discusión del sentido social de estos. Afirma que con la instrumentación de reformas curriculares el término innovación se asoció con el diseño y la aplicación de modelos curriculares. En la década de los 70, debido a la expansión de la educación superior en México, comenzó a enfatizarse la tendencia hacia las innovaciones con base en las teorías educativas en uso y particularmente la vinculación educación-empleo. De hecho, se puede hablar de innovación desde las reformas educativas que ya se han documentado en los estados de conocimiento, las cuales responden a las grandes tendencias económicas tal como en el ámbito internacional, donde se han venido planteado con enfoques corporativistas y desarrollistas.

En un texto reciente, Díaz Barriga F. (2005) afirma, con base en el análisis de la producción en investigación curricular de los 90, que el desarrollo de los modelos y las propuestas curriculares innovadoras en esa década fue motivado por las discusiones académicas en torno a las necesidades y a las características de las instituciones educativas, donde la tendencia predominó hacia los modelos flexibles y por competencias, con una base pedagógica constructivista, contenidos y métodos didácticos integradores en torno a ejes estructurantes y el uso de tecnologías, que responden fuertemente a la visión técnica y pragmática de la formación de destrezas laborales.

La perspectiva fue matizándose con otros referentes epistemológicos más cercanos a los enfoques social y ecológico que Delgado (citada por Díaz Barriga, 2005) propone para definir competencias educativas hacia el bienestar, los valores de equidad e inclusión, la diversidad y adaptación social y la construcción de identidades, traducidas a competencias de carácter holístico que abarcan, con esa misma amplitud, el aprendizaje humano integral. 
El enfoque de la formación del capital humano ha ido perdiendo centralidad y enfrenta alternativas enfocadas a la innovación social. De acuerdo con Pérez (2000, p. 214) "cualquier innovación, aun sin dejar de ser una cierta tecnología y una práctica de reflexión personal sobre un espacio cultural, es -sobre todo- un proyecto social de cambio, de consenso para el logro del interés emancipador"; por ese motivo, resulta más adecuado hablar de capital social.

Herrera y Didrikson (2004, p. 3) proponen el concepto de "innovación crítica”, que en el contexto del currículum universitario impulsa el tránsito hacia un nuevo paradigma de formación, de producción de conocimientos y aprendizajes, sustentado en la articulación de conocimientos en torno a ejes transversales. Reconocen que la propuesta aún se encuentra en debate, pero marcan la pauta que confirma a la innovación crítica como perspectiva de cambio institucional cuya base está en la movilización del conocimiento, su articulación y redimensionamiento hacia métodos, lenguajes, contenidos y técnicas para producir nuevas áreas de conocimiento y un núcleo fundamental de competencias científico-profesionales, metodológicas, de investigación y técnico instrumentales para nuevos modos de producción de conocimiento, factor fundamental de la innovación. Tenemos, entonces, que una de las necesidades de innovar en la educación está en producir nuevo conocimiento pertinente, socialmente significativo.

Carballo (2004) sostiene que el conocimiento es dinámico, está muy vinculado a la realidad de las personas que lo generan y lo viven, a formas culturales que lo hacen posible, lo inhabilitan u obstruyen. Para innovar es indispensable tener conocimiento y potenciarlo, pero, además, se precisa de personas, de las relaciones entre ellas, de mediadores. Respecto al ámbito educativo Motta (2002) considera que su transformación implicará crear las condiciones de una formación integral y continua que revalore el lugar y la importancia de la reflexión y crítica de rigor filosófico, conjuntamente con una crítica histórica y una visión epistémica, no mecanicista, de la ciencia junto a un conocimiento actualizado sobre la importancia y el valor de lo simbólico. Concluye que no es posible una verdadera reforma de la educación sin una reforma del pensamiento, cuyos primeros pasos implican una ecología de la inteligencia colectiva y una ecología de las ideas.

Innovar el currículum, entonces, no puede seguir siendo una cuestión declarativa con una finalidad de papel; tampoco un proceso instrumental pensado y vivido solo por algunos, para justificar mandatos, funciones y ciclos político-administrativos, sino una experiencia 
colectiva que parta de una expectativa de futuro inmediato, de una causa de significado común, de procesos recursivos de reflexión y acción y de un conocimiento enriquecido y encausado por la intersubjetividad.

Con lo anterior se justifica la necesidad de escudriñar las posibilidades de innovación curricular que apunten a la formación de individuos en profesiones, como el turismo, en la que se advierten oportunidades de establecer colectivamente, contenido y significado a los propósitos, los medios y los fines para ser más pertinentes al desarrollar las capacidades de las instituciones y de los individuos para enfrentar la incertidumbre y la complejidad que caracteriza el entorno.

\section{La investigación curricular en turismo}

La investigación curricular en turismo es relativamente nueva; el crecimiento de este como actividad económica y como práctica social y profesional se refleja, como en otros aspectos, en el incremento de la investigación educativa y curricular particularmente en los años 1980 y 1990 en el Reino Unido, cuna del turismo moderno, América del Norte, España y en la región de Asia-Pacífico y Australia. Semejante a lo que sucede con el campo del currículum en general, se ha enfatizado lo instrumental y práctico obviando el sentido fenomenológico de su evolución.

En este apartado se presentan autores que han realizado estudios que van configurando el campo, entre los que se describen algunos planteamientos sobre temas como: enfoques y tendencias (Tribe, 2001, 2002, 2005a; Koh, 1995; Airey y Johnson, 1999; Airey, 2008; Espasandín, Díaz y Quirós, 2010, Vera e Ivars, 2001), contenidos (Inui, Wheeler y Lankford, 2006; Morgan, 2004; Stuart (citada por Airey, 2008); Tribe, 2002; Olsson y Lofgren, 2007), formación (Busby y Fiedel, 2001; Koh 1995; Airey y Johnson, 1999; Morgan, 2004; Tribe, 1997; Morgan, 2002; Inui, Wheeler y Lankford, 2006; Wang, 2008; Espasandín, Díaz y Quirós, 2010; Vera e Ivars, 2001) y modelos curriculares (Scrimshaw, 1983; Lawton, 1989; Squires, 1990; Goodlad, 1995 (citados por Wang, 2008); Tribe, 2002, 2003, 2005; Busby, 2003), entre otros que han abordado diversos temas relacionados con ocupaciones, perfil profesional y conocimiento, cursos, educación turística y posgrado, políticas y prácticas educativas, programas, enfoques de la enseñanza del turismo, requerimientos de formación para los negocios, hospitalidad, gerencia, participación del sector empresarial en la 
formación en turismo, tecnología, perspectiva de los actores, planeación y estudios regionales ${ }^{6}$.

El acceso restringido a documentos de interés para este artículo limitó un análisis más completo sobre el tema; sin embargo, se han considerado aquellos que sustentan los argumentos que aquí se entrelazan.

John Tribe $(2001)^{7}$, estudioso del tema, ubica las tendencias en investigación curricular a partir de tres paradigmas: el científico positivista, el interpretativo y el crítico, el primero de ellos domina la investigación en este campo. En sus diversas aportaciones menciona que los primeros estudios aparecieron a principios de los años 80 con autores como Leiper, Murphy y Stear, quienes en 1981 presentaron trabajos de tipo descriptivo. Tribe ha demostrado que la investigación positivista se ha encauzado a las necesidades de la industria del turismo, mientras que otros aspectos se han ignorado. En 2005, en coedición con David Airey, producen la obra "An International Handbook of Tourism Education", donde se analiza la orientación y el desarrollo de los estudios turísticos a nivel internacional, en regiones como Sudáfrica, Latinoamérica y Reino Unido, centrándose en el currículum como el referente teórico para determinar el estado de la cuestión.

La obra contempla las nuevas tendencias enfocadas al internet, la investigación, el empleo y la calidad en la educación turística. En casos concretos los expertos de diversas áreas muestran el nivel de desarrollo del turismo y su relación con conocimiento y currículum; aportan aspectos esenciales para los programas académicos con fines de internacionalización, profesionalización y enriquecimiento del área disciplinar del turismo.

Tribe (2005a) da cuenta de 302 referencias entre 1974 y 2001, de artículos relacionados con educación y turismo, en los que el $86 \%$ gira en torno al currículum, lo que muestra que especialmente en Europa ha recibido atención el tratamiento de diversos temas como modelos de planificación, análisis crítico del plan de estudios, el perfil descriptivo de la oferta educativa (Reino Unido), educación turística (estudios comparativos), globalización, estudios de opinión sobre la calidad de la oferta educativa, currículum y conocimiento

\footnotetext{
6 Consultar la página http://www.tourismeducation.org/bibliography.htm

7 Profesor en Turismo y Director de Investigación de la Facultad de Ocio y Turismo, Buckinghamshire New University. Estudió su licenciatura, maestría y doctorado en la Universidad de Londres.Es Co-Presidente del Consejo de Educación en la Organización Mundial del Turismo de las Naciones Unidas, redactor en jefe de Annals of Tourism Research y Presidente del Consejo Editorial de la Higher Education Academy Network Journal of Hospitality, Leisure Sport and Tourism Education. Posee un amplio repertorio en investigación sobre temas de Sostenibilidad, Epistemología y Educación en Turismo.
} 
turístico, necesidades de capacitación en la industria, cualificaciones y temas específicos como: enseñanza, aprendizaje, evaluación, progreso y logro de los estudiantes, recursos de aprendizaje y gestión de la calidad y mejora.

En un trabajo anterior, este autor argumenta, entre otras cuestiones, que la investigación curricular debe considerar otras voces, además de la industria, arrojar luz sobre el turismo en un ámbito más amplio, desarrollar una sociedad de turismo no solo para los negocios, sino para todos sus grupos de interés, donde las prácticas deben ser abordadas también a partir de intereses emancipatorios, supuestos que otros estudiosos del tema coinciden en señalar (Tribe, 2001; Koh, 1995 y Airey y Johnson, 1999). Siguiendo a Tribe, afirma que la debilidad del paradigma positivista en su aplicabilidad, no reconoce el sentido y los valores y excluye las cuestiones morales, por lo cual es necesario implicar los enfoques crítico e interpretativo en la investigación curricular en turismo. De acuerdo con el autor, el paradigma crítico se caracteriza por la asunción de una unidad entre hechos y valores con un énfasis en estos últimos; por ejemplo, aplicando la teoría crítica de Habermas, a fin de revelar diferencias y liberar al currículum profesional del dominio técnico, inherente al paradigma positivista.

Airey (2008), por su lado, refiere la evolución de este campo, explorando las formas en que el turismo ha surgido y madurado como práctica, como campo de estudio y cómo se ha reinventado a sí mismo en contextos cambiantes. El análisis, basado en el libro que publicara en coedición con Tribe (2005), se hace a partir de las cuatro etapas o plataformas de evolución científica del turismo, planteadas por Jafar Jafari (2005), estableciendo una correlación con los cambios en la enseñanza del turismo. Cada etapa se define, según el autor, conforme a los cambios paradigmáticos en el mundo occidental, desde la etapa favorable o de industrialización (1960-1970), donde el contenido y fines del currículum se basan en el fuerte crecimiento del turismo. Tribe (citado por Airey, 2008) menciona que los currículos, aunque presentan cierta coherencia en su estructura y marco teórico, no muestran ningún elemento unificador, son más bien pedacitos de conocimiento atomizado procedente de otras disciplinas.

En la etapa de fragmentación o plataforma desfavorable, nace una corriente crítica con respecto a los impactos del turismo (1980-1990) reorientando los enfoques tanto de la investigación como de su enseñanza; la incertidumbre sobre el currículum se refleja en el crecimiento de la oferta educativa y el desarrollo asociado de conocimiento sobre turismo. 
Varios autores, citados por Airey, dan ejemplos de la relación entre el turismo, la educación y la industria turística, como Cooper y Shepherd en 1997; Cooper y Westlake en 1998, del papel de los stakeholders en la educación del turismo; Smith y Cooper en 2000 de los enfoques de competencias para diseñar planes de estudios y Cooper en 2002, de la planificación del currículum, aunque en la generalidad se favoreció el enfoque hacia los negocios y la gestión.

La etapa de referencia o conciliadora, la relaciona el autor con la publicación de la Declaración de Asuntos de Referencia para la Industria Hotelera, de Ocio y Turismo por la Quality Assurance Agency for Higher Education en el año 2000, resultado del debate académico para describir la naturaleza y las características de los programas educativos, definiendo por consenso cuatro áreas claves de conocimiento: conceptos y características del turismo como área de estudio; la estructura y las interacciones en el sector turístico; el papel del turismo en las comunidades y entornos y naturaleza y las características de los turistas, temas que sugieren según el autor, que el turismo va más allá del estudio del sector.

Finalmente, la etapa de madurez o científica se caracteriza por un creciente debate y autocrítica sobre el currículum, en particular, por una concepción más madura de la función de la educación turística. Para los autores el debate no terminó con la declaración de la QAA (2000), sino que ha tomado otro cauce, considerando la naturaleza y dirección del conocimiento influenciado el desarrollo social y de la ciencia, comprometida con las teorías post-estructurales y con la vinculación de lo cultural y la crítica a lo que han denominado "giro cultural" (Tribe, Ateljevic, Aitchison, citados por Airey 2005).

Aunque la tendencia profesionalizante continúa predominando, se manifiesta ya una mayor preocupación, por lo que actualmente debe ser enseñando. Airey evidencia su acuerdo citando a Ronald Barnett (1999), en identificar la necesidad de desarrollar una cultura de la acción crítica en los estudiantes y aprender a lidiar creativamente con la incertidumbre y a Tribe (2002), afirmando que la educación en turismo no se debe limitar únicamente a la acción profesional.

En España, Vera e Ivars (2001) exploran la evolución de los estudios superiores concentrados en la Diplomatura de Turismo, recientemente integrada como carrera universitaria (1996) y una extensa oferta de cursos de posgrado y títulos para cubrir las necesidades de especialización en la formación turística. Se menciona la reciente creación de la Licenciatura de Turismo como estrategia oportuna para fortalecer la educación, la 
investigación y, por ende, la economía española a través del turismo, acorde con la creación de un espacio común europeo. El análisis se llevó a cabo en tres áreas: objetivos, capacidades a desarrollar y planes de estudios, donde se detectó la tendencia uniforme de una formación orientada a satisfacer la demanda de la industria. Entre otras consideraciones, destacan la poca de importancia que se da a las habilidades relacionadas con la orientación de servicio al cliente, con el valor del patrimonio cultural, la comprensión del marco jurídico del turismo y el conocimiento de las estructuras políticas y administrativas en las que se basa el desarrollo del sector.

Espasandín, Díaz y Quirós (2010) realizaron un análisis sobre la educación superior en turismo en España, para definir elementos que orienten las estrategias para su adaptación al espacio europeo de educación. El análisis se centró en cinco de las 80 universidades españolas que ofrecen un título universitario en turismo, seleccionándolas a partir de dos criterios: las contribuciones a las 11 revistas académicas arbitradas de hospitalidad y turismo para los años 2002 a 2006, y la importancia del turismo internacional en la región donde se ubica cada universidad de acuerdo con las regiones españolas de Cataluña, Islas Baleares, Andalucía, Valencia y Madrid, que captaron el 90.1\% de los turistas extranjeros en 2006. Las cinco universidades seleccionadas están en Las Palmas de Gran Canaria, Valencia, Islas Baleares, Alicante y Sevilla.

A partir de los datos obtenidos se estudiaron tres cuestiones relativas a la formación universitaria en turismo: el propósito de los estudios universitarios, las competencias, transversales o genéricas y específicas, que los estudiantes deben desarrollar durante su estancia en la universidad y las importancia de las materias de estudio en las distintas universidades, de acuerdo a la ANECA.

Entre los resultados alcanzados, particularmente en lo que se refiere a las implicaciones en el diseño curricular en turismo, se determinó la tendencia hacia los principios del mercado, lo cual supone la participación de los actores involucrados en la actividad y en el análisis de las demandas educativas que permitan la comparación internacional. Citando a Tribe, 2006 y a Westlake, 1997, los autores confirman que el currículum estará basado en el aprendizaje por competencias y condicionado por las características de madurez y multidisciplinariedad del turismo. Para seleccionar los contenidos se considerarán experiencias curriculares exitosas, así como la demanda que presente la educación en turismo. 
Con relación a los contenidos, otros investigadores han canalizado su trabajo a analizar el grado de turismo desarrollado enfoques alternativos críticos (Inui, Wheeler y Lankford, 2006) y sostienen que hay varios puntos de vista sobre la necesidad de un contenido compartido y diversificado. El sentido práctico y de conveniencia al elaborar el currículum, por ejemplo, ha sido discutido con los argumentos de la diversidad como un factor de desarrollo para la industria del turismo. La falta de acuerdo sobre el contenido de los programas en turismo abre el debate entre un currículum industrial y uno con enfoque científico más amplio (Hall, citado por Wang, 2008); Morgan, 2004; Stuart (citada por Airey, 2008); Tribe, 2002), argumentando que en última instancia se trata de lograr un equilibrio entre las demandas del mercado y las de la sociedad.

En Suecia, Olsson y Lofgren (2007) analizan la selección de contenidos en los programas de turismo mediante la identificación de los discursos sobre el turismo en la Educación Superior, para demostrar su relación con el poder. Este artículo se ocupa del currículum en turismo como un problema político (Englund, citado por Olsson, 2007). Es una investigación con enfoque socio-político que estudia las dimensiones política y moral a través de un análisis genealógico. Para analizar el origen y la estructura del discurso, se remontan a la expansión de la industria del turismo, a la política del turismo sueco y a los subyacentes enfoques disciplinarios del turismo. Al centrar el discurso en el paradigma industrial dominante, se hace visible su poder para limitar otras formas de pensar y hablar sobre el turismo. El discurso industrial puede, por ejemplo, evitar contenidos inherentes al desarrollo sostenible en los currículos de países en desarrollo.

Tribe (2002), por su lado, desarrolla los principios acerca de cómo el currículum en turismo puede ser organizado, partiendo de cuatro ámbitos clave: la acción profesional, la reflexión profesional, la reflexión y la acción liberal. Estos dominios enmarcan un plan de estudios con el objetivo de desarrollar en los estudiantes prácticas filosóficas para ser capaces de ofrecer los servicios demandados en un marco altamente profesional, así como de desarrollar la industria de manera responsable. En ambos casos, la capacidad de reflexionar y examinar críticamente el contenido y las consecuencias del turismo es fundamental. Morgan (2004) argumenta que el objetivo de la educación superior en el turismo es satisfacer las necesidades de los estudiantes, financiadores y empleadores; sin embargo, no hay acuerdo sobre cómo hacerlo mejor. El turismo en el futuro debe ser parte de la economía de la experiencia y, con base en este supuesto, Morgan se manifiesta a favor 
de una educación que considere en mayor medida los valores humanistas, basada en la filosofía y las teorías sociológicas. El desarrollo de las cualidades, como la auto-conciencia, la fantasía y la creatividad en los estudiantes, será necesario para satisfacer las necesidades del futuro.

En cuestión de formación, hay argumentos que se presentan a favor de un currículum básico (Busby y Fiedel, 2001) y otros que defienden una línea de adaptación a las necesidades del mercado (Koh, 1995) o señalan una tendencia altamente profesionalizante (Airey y Johnson, 1999; Morgan, 2004; Tribe, 1997). Morgan (2002) evalúa de forma crítica los programas de estudio y las unidades o cursos que los integran para promover el aprendizaje flexible con el uso de las TIC en Australia, con relación al desarrollo del turismo.

El autor propone, citando a Murphy, Fraser y Webster (1999), cinco vías para mejorar a través de una estrategia de planificación, la flexibilidad en los programas de la universidad: estructura del programa, contenido, métodos de enseñanza y aprendizaje, la interacción y la evaluación del curso. Describe un proceso para introducir prácticas flexibles de aprendizaje y satisfacer las necesidades de una amplia gama de estudiantes separados por distancias geográficas. Inui, Wheeler y Lankford (2006) reafirman la idea de formar individuos calificados para la industria, pero con cualidades reflexivas y críticas que aporten a la sociedad global una mejora de la práctica común en el contexto de desarrollo del turismo, con capacidades para cuestionar la responsabilidad social de la industria.

Wang (2008) en su investigación "¿Tourism education meets the needs of the tourism industry?" desarrollada en Australia, aborda la necesidad de una formación pertinente a las necesidades de la industria turística, ya que más de tres cuartas partes de las universidades en Australia ofrecen estudios de hostelería o turismo a nivel de pregrado o postgrado. En el estudio, manifiesta, se encontró una considerable variación entre las opiniones de los profesionales de la industria y los proveedores de académicos en ese país. Las opiniones recabadas varían en cuanto a la pertinencia de la educación terciaria para el turismo y los méritos relativos a las competencias y habilidades necesarias para trabajar en el sector, en un país considerado líder en los estudios de turismo y hospitalidad en la región de Asia Pacífico. En el contexto australiano, afirma el autor, los programas de estudios de turismo no han seguido el ritmo de la evolución de la calidad en educación, ni de la calidad de los servicios necesarios para atender al sector turístico. 
Como resultado de ello, la industria del turismo se resiste a reconocer el valor de los graduados universitarios y acepta que un grado no es un pasaporte para incursionar en la gestión del turismo, estableciendo la existencia de una importante brecha entre los sectores educativo y turístico. Bernthall (citado por Wang, 2008) indica que la participación de la industria del turismo ha significado un desafío constante a la educación turística. Para Wang, Goodenough y Page en 1993, Cassels en 1994 y Botterill en1996, sugieren concretar medidas prácticas para aprovechar las aportaciones de los empleadores y crear, mediante la deliberación, las conexiones necesarias entre industria y educación superior para una educación pertinente. El estudio se basa en datos concretos obtenidos de otras investigaciones y los propiamente generados con métodos cualitativos.

Espasandín, Díaz y Quirós (2010) citan al Sheldon et al., (2007) para destacar la opinión de 16 expertos en turismo identificando los valores, conocimientos y capacidades que requieren los egresados para contribuir al desarrollo del horizonte 2010-30, describiendo cuatro categorías de formación surgidas de su investigación como: la administración de destinos (gestión de redes reales y virtuales, habilidades de intercambio de conocimientos, capacidad de respetar y trabajar con todas las partes interesadas, la gestión de los sistemas complejos adaptativos, las habilidades de gestión ambiental); las competencias políticas y éticas (comportamiento ético: la demostración y la motivación, integración de los valores humanos básicos en el lugar de trabajo, cabildeo y la capacidad de influir en el proceso político); las capacidades mejoradas de los recursos humanos (trabajo en equipo, la escucha efectiva y la negociación, motivación y liderazgo, trabajando con el proyecto distribuido, virtual equipos, inteligencia emocional) y las habilidades empresariales (trabajo en equipo, la escucha efectiva y la negociación, motivación y liderazgo, trabajando con el proyecto distribuido, virtual equipos, inteligencia emocional).

Citando nuevamente a Sheldon et al., (2008), mencionan que los programas educativos (en Europa) están destinados a lograr un turismo tipo certificación TedQual, a fin de lograr programas efectivos y, en consecuencia, asegurar la calidad de la educación en el turismo. De igual modo, Vera e Ivars (2001) plantean la necesidad de la formación de competencias laborales tal como las han definido autores como Le Boterf en sus trabajos presentados en 2000 y 2001 y el conjunto de competencias definidas por la Agencia Nacional de Evaluación de la Calidad y Acreditación (ANECA) en su Libro Blanco que publicara en 2004 para los estudios universitarios en turismo, analizando aspectos como los 
créditos, los contenidos y las áreas de conocimiento, para valorar los atributos que deben adaptarse a los estudios turísticos de nivel universitario en la región.

Otros investigadores del currículum han abordado aspectos del diseño de modelos para la educación en turismo desde la década de 1980 (Scrimshaw, 1983; Lawton, 1989; Squires, 1990; Goodlad, 1995 (citados por Wang, 2008); Tribe, 2002, 2005), estableciendo diversos principios para el ordenamiento del currículum. Tribe (2003) realizó un estudio sobre las percepciones de los profesores acerca de la calidad de la educación superior en el turismo en Inglaterra e Irlanda del Norte. Su metodología se basa en la triangulación de datos cualitativos y cuantitativos obtenidos de una encuesta a setenta y nueve profesores, de la auditoría institucional y de las evaluaciones realizadas por la Quality Assurance Agency for Higher Education (QAA).

Los seis aspectos curriculares que se consideraron fueron el diseño, el contenido y la organización, la enseñanza, aprendizaje y evaluación, la progresión y el rendimiento del estudiante, el apoyo y orientación al estudiante, los recursos de aprendizaje y gestión de la calidad y la mejora. El estudio demuestra que las metas y los objetivos fijados en el currículum se cumplen, aunque el problema clave de la calidad radica en cómo animar al personal docente a concentrarse en los alumnos y no los temas. Los principales retos que se desprenden de la encuesta son la necesidad de actualización docente y la innovación curricular, vista como una debilidad. Se menciona un grupo de factores que hacen que la calidad sea más difícil de lograr: el bajo nivel de ingreso, la diversidad de estudiantes que ingresan y el aumento de alumnos por aula.

John Tribe propone un modelo cuyo propósito es definir los elementos esenciales de un currículum para el pensamiento y la acción en el mundo del turismo, en donde exista una conjunción entre el profesional liberal y el profesional en acción. En "The Philosophic Practitioner" (2002), realiza una distinción entre un currículum profesional para el empleo y un currículum liberal para el pensamiento y la reflexión. El modelo consta de cuatro planos profesionales clave: la acción profesional, la acción liberal, la reflexión liberal y la reflexión profesional, a partir de los cuales es posible determinar un espacio curricular para la práctica filosófica en el turismo, que abarca los cuatro dominios del modelo de Tribe y que representa una síntesis de la dicotomía acción-reflexión. La acción profesional se refiere a las acciones de los empleados del turismo y su objetivo es preparar para la eficacia en el trabajo. 
La acción liberal requiere el paso extra de transferir el pensamiento crítico y la comprensión del mundo del turismo en la acción; produce cambios en los niveles individual y social. Los intereses vocacionales y liberales en el currículum de la educación superior en turismo son raramente sintetizados. La reflexión liberal se ubica en la teoría crítica y conduce a una visión más allá del trabajo. La reflexión profesional es un énfasis en la deliberación, evaluación y modificación de habilidades para la industria del turismo y el conocimiento. Para Tribe, un currículum en turismo que forma profesionales filosóficos, es una manera de lograr el equilibrio entre la misión social de la universidad y las necesidades en el campo del trabajo.

Busby G. (2003) analiza el caso de la Universidad de Plymounth en el que se aplica un modelo curricular basado en la sustentabilidad ambiental, a fin de formar la conciencia ambiental en sus egresados, en donde los asuntos de la comunidad local son ampliamente abordados evidenciando los resultados positivos que se han obtenido a través de la producción de artículos especializados en el tema, de sus egresados.

Desde luego, el conjunto de argumentos que se han presentado hasta ahora dejan ver en su diversidad la preocupación por definir la orientación de los currículos en el campo educativo del turismo, enmarcada en dos grandes áreas de formación: la profesión en su aspecto de producción (industria y negocios) y el turismo como un objeto de reflexión y acción educativa, que en realidad se encuentran determinadas por las dos grandes perspectivas teóricas que tradicionalmente se contraponen en el debate curricular: instrumentalista y crítica, ante las cuales no se ha logrado un consenso que determine, por lo menos, los contenidos básicos en los programas de formación universitaria en turismo. Ante este panorama, encontramos que Tribe afirma, en el capítulo "Tourism, Knowledge and Currículum" (2005b), que la teoría y la metodología del diseño curricular no están, dentro de estos análisis, en el primer plano.

Define el "espacio curricular" como un concepto a partir del cual se delibera sobre tres importantes aspectos: primero la demostración de que cuando el currículum es enmarcado, habrá aspectos que quedan dentro e inevitablemente otros que serán excluidos, es decir, cualquier currículum puede ofrecer solamente una selección de conocimientos; segundo, que existen fuerzas potenciales de varios aspectos que influyen al turismo y que a partir de estas dos cuestiones, cualquier currículum será cuestionado. 
En este recorrido, que no pretende ser exhaustivo, se nota que en los programas educativos del turismo, las reformas e innovaciones curriculares desarrolladas en distintos contextos, determinan perspectivas teóricas y epistemológicas como base para su construcción, sus orientaciones o adaptaciones, que se han establecido desde la percepción epistemológica propia del objeto de estudio del turismo que mucho se relaciona con los modelos económicos prevalecientes en cada etapa histórica de su evolución. De este modo, nos encontramos con modelos curriculares que, en general, se insertan en posturas teóricas orientadas a la productividad y la competitividad económica y que han obviado la perspectiva humana y planetaria en el desarrollo teórico-práctico del turismo.

Hasta aquí, las experiencias se han documentado a partir del análisis teórico y de investigaciones para proponer mejoras desde lo instrumental y práctico, obviando en la mayoría de los casos argumentos basados en el tipo de conocimiento implícito acerca de los procesos que conllevan el sentido y significado de una profesión, respecto a su proyección, su contexto y su sentido social y humano, que indudablemente contiene un importante presupuesto de conocimientos, percepciones, enfoques y creencias de los partícipes directos e indirectos del diseño curricular, de tal modo que los fines de la formación en el turismo, correspondan a los nuevos modos de mirar su objeto de estudio y de formación.

En este marco existe una línea en desarrollo de construcción de conocimiento teórico acerca del turismo como objeto de conocimiento y otra referida a los aspectos educativos, que poco han trascendido a la construcción de modelos curriculares en la formación profesional. Para ser más pertinentes con la dinámica actual y las finalidades que hoy se le atribuyen al conocimiento, como factor de mejoramiento de la economía y de la calidad de vida (Gibbons, 1998), es imperativo analizar los nuevos enfoques con los que se intenta comprender un fenómeno de la magnitud del turismo y replantear los modos de abordaje, particularmente desde la concepción curricular.

En este eje de análisis implicaría profundizar sobre cuestiones de naturaleza comprensiva, tales como los paradigmas y los contextos de aplicación, para pensar asertivamente en la orientación y en los contenidos curriculares, acudiendo así a una actitud crítica hacia las decisiones curriculares con plena conciencia de las implicaciones que han de producirse en la práctica educativa, en la formación de individuos y su trascendencia como un ejercicio de responsabilidad social de la educación superior. 


\section{Retos y perspectivas de la innovación curricular en turismo}

La Organización Mundial del Turismo (2002) plantea la importancia de formular currículos innovadores basados en toda la experticia y el conocimiento posibles, destacando que son pieza clave para la competitividad y el éxito de los destinos turísticos, lo que reafirma la necesidad de formar profesionales capaces de proponer y desarrollar proyectos y prácticas que atiendan necesidades concretas, comprometiendo a las instituciones a trazar rutas alternativas en la educación.

Aguiló (1999) afirma que la investigación sobre enseñanza y formación en turismo se desarrolló con mayor fuerza durante los años noventa; hace referencia a reuniones celebradas bajo esta temática, como la Conferencia Internacional sobre la Enseñanza del Turismo realizada en Surrey en 1988; la Conferencia de Calgary en 1991 y la Conferencia sobre la Educación Turística en Europa realizada en Valencia en el año de 1992. Menciona que en Estados Unidos, la formación turística fue tema de investigaciones y motivo de la aparición del Journal of Hospitality and Education Research (1988) y del Hospitality and Tourism Educator.

La autora señala que se han realizado algunos estudios generales acerca de la formación en turismo desde la década de los 80 por Jafari y Ritchie (1981), Kaplan (1982), Hawkins y Hunt (1988), pero asegura que, en la mayoría de los casos, la preocupación versa sobre dos aspectos principalmente: el tipo de contenidos (materias) que deben conformar los programas de formación turística y su capacidad de respuesta a las expectativas del sector.

Atribuye esta tendencia al repentino crecimiento del turismo de masas, a su incremento en zonas poco desarrolladas en donde se concibe como una cuestión básicamente de relaciones humanas y a la inminente segmentación del mercado propia del nuevo siglo, en donde las necesidades de capital humano apremian y las oportunidades de reflexionar sobre estos fenómenos no han encontrado suficiente tiempo y espacio.

Principalmente en los Estados Unidos la tendencia marca el surgimiento de escuelas de negocios y gestión empresarial con programas de dos años, (cita a Goodman y Spragne, 1991), disminuyendo la demanda en programas de gestión turística, con contenidos basados en aspectos económicos y sociales del turismo, acordes al modelo europeo.

Con otra perspectiva, Rojas (2003) analiza la relación turismo y educación como un ámbito de acción extenso, que aporta una gama de posibilidades pedagógicas para fortalecer los aprendizajes, la identidad, la cultura de los estudiantes de nivel básico en Chile, 
con aportes temáticos (naturaleza, arte y cultura) y de fortalecimiento ético, estético y valoral. Colom y Brown (1993) hicieron en su momento aportaciones en la clasificación de las áreas pedagógicas que pueden definirse a partir del turismo: educación para la comprensión, interculturalismo, ocio y tiempo libre y educación ambiental.

García y Valenzuela (2009) realizaron un estudio de educación comparada de veinticinco planes de formación profesional en turismo que se ofertan en la Ciudad de Puebla, Méx., determinando la orientación altamente profesionalizante, en torno a las áreas de administración, idiomas, restaurantes y bares, investigación, contabilidad y derecho.

Maciel (2009) advierte la importancia de insertar la educación ambiental en las carreras de turismo para formar ciudadanos capaces de contribuir al equilibrio entre el ser humano y su ambiente. Capellano, Köche y Rizzon (2010) proponen una pedagogía de investigación en la formación de Licenciados en Turismo, para la comprensión de los problemas epistemológicos, metodológicos y de lenguaje discursivo, que desarrolle competencias de orden superior ante las problemáticas sociales. Carrera (2010) plantea la creación de un sistema académico por competencias para la Escuela de Turismo y Hospitalidad de la Pontificia Universidad Católica de Ecuador, para fomentar el desarrollo del turismo sostenible considerando la competitividad laboral.

Un trabajo de corte reflexivo e interpretativo acerca de un programa de turismo en la Universidad Autónoma del Estado de México Medina (1999) propone, con base en el análisis participativo, un modelo innovador para mejorar la práctica educativa desde la intervención del profesor como principal mediador del currículum. En otro trabajo, "La gestión participativa como eje impulsor del cambio en el proceso de innovación curricular de la Licenciatura en Turismo de la UAEM" (2003), la autora conduce la investigación al análisis interpretativo del rol del profesor en los procesos de gestión del currículum, considerando su valor como "espacio privilegiado para analizar la comunicación entre ideas y valores por un lado, y la práctica por otro (...) la relación teoría-práctica en los planos social y cultural” (Medina, 2003, p. 269), asumiendo una postura comprensiva para descubrir el sentido de la intensión y la acción del profesor como actor social que interviene y define el currículum a partir de su cultura.

Con los estudios antes citados, se advierte una línea de investigación desde la perspectiva interpretativa, como pauta para propiciar la sistematización de conocimiento que entrañe la complejidad del currículum universitario en turismo, en tanto que aporta elementos 
de comprensión al vincular pensamiento, acción y contexto, descubrir y fundamentar lo esencial en la formación de individuos, asumiendo el reto de saber, saber ser, hacer y convivir en una sociedad marcada por la incertidumbre y la complejidad.

Así, se hace frente a la tarea de explorar los modelos formativos que no escapan al debate educativo actual y que por fortuna se examinan en el ámbito de la formación en turismo. Barrado Timón (2001) señala que la educación en este ámbito se enfrenta al reto de la interdisciplinariedad derivada de la complejidad del sector, y esto es así porque se configura cada vez con mayor incidencia un perfil horizontal y abierto a todas aquellas ciencias que intervienen en el análisis de la actividad, para ser capaces de planificar y gestionar el turismo en toda su complejidad.

Tamayo y Peñaloza (2005), enfatizan la relación turismo-educación y la manera en la que se implican una y otra área de estudio y de conocimiento, a través de la formación turística y los contenidos educativos del turismo. Describen los aportes de la ciencia educativa a la fundamentación teórico metodológica de los diversos proyectos de formación de profesionales en turismo. Gómez Nieves (2005) argumenta la necesidad de adecuar la investigación y la educación superior en turismo a los desafíos globales como las transformaciones tecnológicas, la era de la información y los avances científicos.

En México, instituciones públicas que ofrecen carreras de turismo (U. Autónoma de Baja California, U. Autónoma de Colima, U. Autónoma del Estado de México, U. Autónoma de Guadalajara, entre otras, han desarrollado experiencias para la formulación de currículos innovadores implicando procesos que dan pauta para delinear los nuevos propósitos y contenidos de la formación en turismo, aunque Medina $(1999,2003)$ admite la falta de marcos teórico-metodológicos y referenciales que configuren un contexto de análisis para producir reformas curriculares que actualicen el sentido de la profesión turística, en las que confluyan diversos campos problemáticos del saber y del hacer.

Se observa, entonces, la necesidad de innovar las cualidades y estructuras sobre las que se cimenta el turismo, entre ellas la educación, puesto que como señala Urry (2001), la movilidad turística será uno de los factores que reconstituyan la vida social de manera compleja y desigual en el proceso de globalización, a partir del significado de los objetos, los sentidos, el tiempo y el espacio. Dicho cambio deberá ser estudiado en su diversidad contextual, porque al enfrentarnos a un mundo globalizado, los patrones culturales y los estilos de vida social presentarán procesos constantes de transformación. 
Particularmente, la educación en turismo se enfrenta a procesos de cambio que le impulsan a reestructurarse y adaptarse a las exigencias del contexto; para ello, es preciso asumir una postura epistemológica donde los procesos de formación en las instituciones de educación superior se enfoquen al desarrollo de seres humanos conscientes y sensibles, capacitados para proponer y desarrollar prácticas innovadoras, reconociendo al turismo como un fenómeno complejo, dinámico y cambiante que se encuentra desbordado al enfrentar dificultades de estudio en escenarios de constante cambio social, lo cual implica un abordaje inter y transdisciplinar.

En una perspectiva compleja, la reflexión apuntaría a nuevas formas de relación entre los actores, nuevos modelos de gestión de los procesos y de su evaluación, articulados con los contextos científico/disciplinar, institucional y social; que aporten elementos para transitar hacia paradigmas innovadores del currículum en turismo, que como objeto de estudio, es en esencia de naturaleza multirreferencial, inter y transdisciplinar.

\section{Conclusiones}

Al aproximarse a un estado de conocimiento en la investigación curricular, se identificaron corrientes donde se observan los enfoques que han dominado por décadas una visión instrumentalista con diversas vertientes, que en la década de los años 90 dieron comienzo a un período de cambio en los modos de abordar el currículum, proporcionando la bases para construir proyectos acordes a la nueva realidad que enfrenta la educación superior universitaria.

En general, el acercamiento a la investigación curricular enmarca el ejercicio de búsqueda y reflexión en torno al currículum para la formación profesional en turismo, en donde prevalece el paradigma técnico-instrumental, cuantitativo, industrial con el que se ha investigado y concebido el currículum en esta área de conocimiento. Ciertamente, se perfila una transición lenta y dispersa en las concepciones que sustentan la formación profesional en turismo, por lo que las reflexiones finales en algunos trabajos concluyen en la necesidad imperiosa de transitar hacia otros enfoques que rebasen los supuestos instrumentalistas; se asume que la realidad es mucho más compleja y comporta situaciones que ameritan una visión holista, crítica, compleja de la formación, más allá de la respuesta a las necesidades de desarrollo sectorial. 
El currículum universitario en turismo precisa de ejes que integren la perspectiva multidimensional de sus objetos de estudio, a través de procesos de transformación que solo pueden darse en comunidades capaces de desarrollar la reflexión, la creatividad, el autoaprendizaje y la innovación, creando por sí mismas espacios de interlocución y escenarios de interacción en contextos que promuevan la práctica social en la construcción de modelos curriculares, como ejercicio permanente de reflexión y crítica sobre la relación entre la sociedad, la ciencia, la escuela y los actores. La formación profesional para hoy y el futuro ya no es de carácter instrumental; en el turismo, como en otras áreas, es urgente potenciar las capacidades individuales y colectivas en estrecha vinculación con las problemáticas humanas, sociales y del entorno.

Para superar la perspectiva dominante en los estudios turísticos universitarios, es necesario rescatar el papel preponderante de una comunidad que reconozca la relación entre las dimensiones del sujeto y el objeto en su contexto, que despliegue su capacidad para conocer y comprender que el problema de la educación, es concebir el currículum exclusivamente desde la perspectiva normativa, cuando en la realidad es el producto de la interacción en distintos niveles y ámbitos, lo que implica movimiento recurrente entre lo real, lo ideal, lo deseable y lo posible; conjugar múltiples epistemes surgidas de la necesidad de validar las teorías en la práctica, pensar y actuar en términos de lo formativo, involucrando los saberes perceptuales que se consideraban irrelevantes (sentidos, significados, intención, intuición, incertidumbre) y que hoy mantienen una posición privilegiada en el orden de los saberes fundamentales, para trascender a lo praxiológico de la educación.

Se propone una vía de construcción de modelos educativos en turismo, que recupere el significado epistémico del currículum, como forma de construcción de conocimiento para la comprensión de lo esencial en los procesos de innovación curricular. Se intenta generar un enfoque en el que los procesos metodológicos desarrollen significado y legitimen el resultado de los saberes integrados que provienen de diferentes fuentes conceptuales, contextuales y disciplinarias para dar validez y congruencia social a la determinación conceptual y contextual de los propósitos de la formación en turismo, sus alcances y sus límites, sus contenidos, métodos, estrategias, técnicas y recursos para aprender.

Si bien es cierto que los paradigmas condicionan la visión sobre el conocimiento y la ciencia y expresan valores que, a su vez, determinan el actuar de los sujetos, entonces es necesario descubrir cuáles son los principios y categorías cognitivas, valorativas, epistémicas 
que subyacen a las posturas teóricas. Evidentemente, estas cuestiones exigen una justificación inter y transdisciplinaria; fundamentar modelos para la formación profesional en turismo que, como afirma Polo (2011), organicen la formación de un modo compartido entre los docentes y alumnos, generando escenarios problemáticos que sean abordados desde disciplinas que se conjuguen para propiciar respuestas, dando pauta a paradigmas articuladores de lo pedagógico y lo epistemológico, creando nuevas categorías y unidades para analizar la formación. Pero sobre todo, delimitando las posibilidades solo con la medida de las potencialidades de un tipo de aprendizaje "hiper" capaz de generar nuevos recorridos y establecer conexiones inter y transdisciplinarias

Considerar como giro epistemológico la reflexión de nuevas formas de relación entre los actores y los objetos permite configurar el conocimiento desde una postura epistemológica compleja (Najmanovich, 2001) acorde al siglo XXI, con métodos para abordar de manera holística, la construcción de objetos de conocimiento. Adoptar enfoques complejos se caracteriza por "pensar en términos de interacciones con la posibilidad de salir del círculo vicioso del método a priori y habilitar un pensamiento fluido, capaz de adoptar diversas configuraciones sin llegar a la rigidez del cristal y sin desvanecerse como el humo" (Najmanovich, 2001, p.11).

Aquí, el conocimiento es entendido como configuración que surge de la interacción multidimensional; ya no es un producto rígido y externo que se concreta y establece en una teoría, sino una actividad que se manifiesta en el texto y en el discurso. La configuración, dice la autora, surge del encuentro de los seres humanos con el mundo al que pertenecen y destaca la dimensión interactiva, multidimensional y fluida de las nuevas tecnologías que propician un cambio en la concepción del conocimiento como producto, al conocimiento como actividad (en red), que enfatiza el pensamiento configurativo.

El turismo, por su capacidad de reinventarse en diversos aspectos, desarrolla nuevos conceptos y prácticas, crea nuevos destinos, formas de organización y gestión pública, empresarial y comunitaria, nuevos consumidores, tecnologías, formas de producción, enfoques de planificación, relaciones e interacciones, cuyos efectos es necesario analizar y valorar lo que define múltiples elementos configurativos. Como objeto de análisis tiene que verse como campo crítico, dadas las grandes implicaciones que conlleva, desde la práctica más elemental hasta su desarrollo como fenómeno social complejo, desde su evolución como fenómeno masivo hasta sus manifestaciones y prácticas más especializadas; ofrece 
múltiples posibilidades de analizar y comprender aspectos de la conducta social y humana, que pueden ser determinantes en el devenir de las sociedad global; de hecho se considera al turismo uno de los factores globalizantes de mayor impacto socioambiental. Es una de las actividades humanas más gratificantes y significantes como práctica social y de las más complejas como objeto de análisis, porque se relaciona, al mismo tiempo, implícita o explícitamente con varias esferas del desarrollo humano.

El turismo inició hace más de un siglo como una actividad lúdica y educativa, que por su dinamismo y alto potencial de rentabilidad se convirtió pronto en una actividad económica muy redituable, que comenzó a generar diversos efectos en la sociedad y en el entorno. Ambas características, llevaron más tarde a la necesidad de insertarlo en las instituciones educativas como un campo propicio de profesionalización, que paulatinamente fue generando su propio campo de estudio y actuación en la academia.

Por este motivo, el turismo plantea desafíos educativos para adaptar dimensiones mucho más amplias, incorporar escenarios innovadores y flexibles, para enseñar, aprender e investigar, integrar enfoques disciplinarios, formas de pensamiento, culturas, saberes y contextos en los que se desarrollan problemáticas de naturaleza técnica y humana, sobre las cuales el profesional en turismo como agente que ostenta la unidad de conocimiento y experticia, debe comprender y resolver.

El turismo no puede seguirse pensando como un fenómeno pueril, sino como un acto inherente a la naturaleza social humana, siempre cambiante y en movimiento. Por eso, una perspectiva que aporte nuevos ideales para formarse desde la universidad implica estudiarlo y aprehenderlo sintetizando sus múltiples dimensiones, considerando que no existen modelos únicos y que toda propuesta curricular debe ser deconstruida, en sus aspectos técnico, pedagógico y didáctico, dando pauta a procesos y prácticas innovadoras que en suma sean sensibles a nuevas dinámicas que emergen en los planos tanto social, como educativo, disciplinar y curricular. Se aspira a formar profesionales capaces de abordar los procesos en su complejidad, para la comprensión profunda de los hechos, como referente para la intervención y transformación de la realidad. Diseñar los currículos para tal efecto no puede inscribirse en un paradigma que simplifique la realidad, al adoptar enfoques y métodos mecanicistas e instrumentalistas, que separan el componente esencial del pensamiento en acción y limitan la concepción holística y dialéctica de un proceso continuo de construcción de conocimiento curricular en turismo. 


\section{Referencias}

Aguiló, Eugeni. (1999). Consideraciones en torno a los trabajos e investigaciones sobre calidad en la formación turística. Revista Cuadernos de turismo, (4). Recuperado de http://revistas.um.es/turismo/article/view/22941

Airey, David and Johnson, Sussan. (1999). The Content of Degree Courses in the United Kingdom, 20. Tourism Management. Recuperado de http://www.sciencedirect.com/science/article/pii/S026151779800079X

Airey, David and Tribe, John. (2005). An International Handbook of Tourism Education. United Kingdom: Elsevier Ltd. Recuperado de http://www.lavoisier.fr/livre/notice.asp?id=OOSWOKAKXXLOWJ

Airey, David. (2008). Tourism Education: Tourism Education: Life Begins at 40. University of Surrey. Recuperado de 2011 de http://epubs.surrey.ac.uk/1136/1/fulltext.pdf

Barrón, Concepción. (2010). Curriculum, formación y vinculación en la educación superior: tres ejes de investigación educativa. México: UNAM. Revista Digital Universitaria. Recuperado de 2011 de http://www.revista.unam.mx/vol.11/num2/art21/int21a.htm

Braslavsky, Cecilia y Cosse, Gustavo. (2006). Las Actuales Reformas Educativas en América Latina: Cuatro Actores, Tres Lógicas y Ocho Tensiones. Revista Iberoamericana sobre Calidad, Eficacia y Cambio en Educación, 4(2).Recuperado de http://redalyc.uaemex.mx/redalyc/html/551/55140202/55140202.html

Busby, Graham and Fiedel, Daniela. (2001). A contemporary review of tourism degrees in the UK. Journal of Vocational Education and Training 53(4). Recuperado de http://www.tandfonline.com/loi/rive20

Busby, Graham. (2003). The Concept of Sustainable Tourism within the Higher Education Curriculum: A British Case Study. Journal of Hospitality, Leisure, Sport and Tourism Education. University of Plymouth. Recuperado de http://fama2.us.es:8080/turismo/turismonet1/economia\%20del\%20turismo/turismo\%20s ostenible/concept\%20of\%20sustenaible\%20tourism\%20within\%20higher\%20education .pdf

Capellano, Marcia M., Köche, José C. y Rizzon, Luis A. (2010). Formación del Licenciado en Turismo. Investigación, epistemología y lenguaje. Revista Estudios y Perspectivas del Turismo, $19 . \quad$ Recuperado http://estudiosenturismo.com.ar/PDF/V19/v19n5a09res.pdf

Carballo, Roberto. (2004). Innovación, Conocimiento y Espacios de Aprendizaje: De los Inhibidores a los Sublimadores. Emprendedores y Creación de Empresas: Aula Abierta, (21). Recuperado de http://www.madrimasd.org/revista/revista21/aula/aula2.asp 
Carrera, Patricia. (2010). Diseño del Sistema Académico por Competencias de la Escuela de Turismo y hospitalidad de la Pontificia Universidad Católica de Ecuador. Revista Gestión Turística, (13). Recuperado de http://www.redalyc.org/articulo.oa?id=223314810005

Colom, Juan y Brown, Geraldo. (1993). Turismo y Educación. Bases para una pedagogía del turismo. Revista Española de Pedagogía, 51(194). Recuperado de http://dialnet.unirioja.es/servlet/articulo?codigo=23488

Creswell, John W. (2005). Educational Research: Planning, Conducting, and Evaluating Quantitative and Qualitative Research (2ª ${ }^{-}$ed.). Upper Saddle River: Pearson Education Inc.

Creswell, John W. (2009). Research Design. Qualitative, Quantitative and Mixed Method Approaches (3rd. ed.). United States of America: SAGED Publications.

Díaz Barriga, Ángel. (1988). Tendencias e Innovaciones Curriculares en la Educación Superior. Ponencia Presentada en el Foro Nacional de Innovaciones en la Educación Superior. Monterrey, México Recuperado de http://publicaciones.anuies.mx/revista/71/1/2/es/tendencias-e-innovacionescurriculares-en-la-educacion-superior

Díaz Barriga, Ángel. (2003). La investigación curricular en México. La década de los Noventa. México: COMIE-CESU-UNAM-SEP. Recuperado de http://densev.gob.mx/biblioteca/modelo integral/Investigacion curricular en Mexico A Diaz Barriga.pdf

Díaz Barriga, Frida y Lugo, Elisa. (2003). Desarrollo del currículo. En: Ángel Díaz Barriga, (Coord.), La investigación curricular en México. La década de los noventa (pp. 68-123). México: UNAM. Recuperado el de http://densev.gob.mx/biblioteca/modelo integral/Investigacion curricular en Mexico A Diaz Barriga.pdf

Díaz Barriga, Frida. (2005). Desarrollo del currículo e innovación: modelos e investigación en Ios noventa. Revista Perfiles Educativos, Tercera Época, XXVII(107). Recuperado de 2011 de http://www.redalyc.org/articulo.oa?id=13210704

Didrikson, Axel y Herrera, Alma. (2004). Innovación crítica Una propuesta para la construcción de currículos universitarios alternativos. Revista Perfiles educativos, 26(105-106). Recuperado de 2011 de http://redalyc.uaemex.mx/src/inicio/ArtPdfRed.jsp?iCve=13210602

Dussel, Inés. (2006). Estudio sobre gestión y desarrollo curricular en países de América Latina. FLACSO/Argentina. Ponencia presentada en la Segunda Reunión del Comité Intergubernamental del Proyecto Regional de Educación para América Latina y el Caribe. Santiago de Chile: PREALC/UNESCO. Recuperado de http://dev.elcorreo.eu.org/IMG/pdf/doc-1252.pdf 
Espasandín, Francisco; Díaz, Carmen y Quirós, Francisco J. (2010). Higher education of tourism in Spain and its adaptation to the European higher education area. Revista de Administração Pública. Rio de Janeiro. Recuperado de http://redalyc.uaemex.mx/redalyc/pdf/2410/241016587008.pdf

Fabara, Eduardo y Hernández, Ma. de Lourdes. (2003). La Investigación sobre Eficacia Escolar en Iberoamérica: Revisión Internacional del Estado del Arte. La Educación y la Investigación Educativa en América Latina. Bogotá: Convenio Andrés Bello. Centro de Investigación y Documentación Educativa. Recuperado de http://books.google.com.mx/books?hl=es\&lr=\&id=z4kjWSrdetlC\&oi=fnd\&pg=PA11\&dq= La+Educaci\%C3\%B3n+y+la+Investigaci\%C3\%B3n+Educativa+en+Am\%C3\%A9rica+L atina+Fabara+y+hern\%C3\%A1ndez\&ots=D4e49B1Nft\&sig=4JUY1 se2qcXqlbg6K2cak HDw $Y \# v=0 n e p a g e \& q \& f=$ false

Ferrer, J. Guillermo, Valverde, Gilbert A. y Esquivel, Juan Manuel. (1998). Aspectos del curriculum prescrito en América Latina: Revisión de tendencias contemporáneas en curriculum, indicadores de logro, estándares y otros instrumentos. Lima, Perú: PREALGTEE-GRADE. Recuperado de http://m.preal.org/detalle.asp?det=806

Ferrer, Guillermo. (2004). Las reformas curriculares de Perú, Colombia, Chile y Argentina: ¿Quién responde por los resultados? Documento de Trabajo 45. Lima, Perú: Grade. Recuperado de http://ageconsearch.umn.edu/bitstream/37735/2/ddt45.pdf

García, Vianey y Valenzuela, Gloria A. (2009). Los Programas de Formación Profesional en Turismo en la Ciudad de Puebla. Ponencia presentada en X Congreso Nacional de Investigación Educativa en México COMIE. Veracruz, México. Recuperado de http://www.comie.org.mx/congreso/memoriaelectronica/v10/pdf/area tematica 02/pone ncias/1426-F.pdf

Gimeno, José. (2008). Educar por Competencias, ¿Qué hay de nuevo? Madrid: Morata.

Gimeno, José. (2010). Saberes e incertidumbres sobre el currículum. Madrid: Morata.

Gomez, Salvador. (2005). Los nuevos desafíos de la Educación Superior y de la Investigación Turística de México. Anuario Turismo y Sociedad (4), Recuperado de http://papers.ssrn.com/sol3/papers.cfm?abstract id=1512614

Grundy, Sherley. (1998). Producto o praxis del currículum. Madrid: Morata.

Inui, Yuka; Wheeler, Daniel and Lankford, Samuel. (2006). Rethinking tourism education: what should schools teach? Journal of Hospitality, Leisure, Sport and Tourism Education, 5(2). Recuperado de http://www.heacademy.ac.uk/assets/hlst/documents/johlste/vol5no2/0122.pdf

Jafar, Jafari. (2005). El turismo como disciplina científica. Department of Hospitality and Tourism. University of Wisconsin-Stout. Recuperado de http://revistas.ucm.es/index.php/POSO/article/download/POSO0505130039A/22996. 
Kemmis, Stephen. (1988). El currículum más allá de la teoría de la reproducción. Madrid: Morata.

Koh, Khoon. (1995). Designing the four-year tourism management curriculum: A marketing approach. Journal of Travel Research, 34(1). Recuperado de http://jtr.sagepub.com/content/34/1/68.short

Korstanje, Maximiliano. (2009). Turismo: un nuevo enfoque disciplinario para la enseñanza académica. TuryDes 2(5). España: Universidad de Málaga. Recuperado de http://www.eumed.net/rev/turydes/05/mk2.htm

Maciel, Fernanda. (2009). Educación Ambiental y Turismo. Una formación holística, interdisciplinaria y de futuros educadores. Revista Estudios y Perspectivas del Turismo, 18(1). Recuperado de http://www.estudiosenturismo.com.ar/PDF/V18/v18n1a6.pdf

Magendzo, Abraham. (2006). Recontextualización Curricular: Campo de recontextualización oficial y campo de recontextualización pedagógica. Recuperado de http://mt.educarchile.cl/mt/amagendzo/archives/2006/11/

Malagón, Luis Alberto. (2004). El currículo: dispositivo pedagógico para la vinculación universidad-sociedad. México. Revista Electrónica de la Red de Investigación Educativa, 1. Recuperado de http://revista.iered.org

Medina, Lourdes. (1999). El diseño curricular. Análisis de la licenciatura en turismo de la UAEM (Colección Sol y Ciencia. No.5). Toluca: Universidad Autónoma del Estado de México

Medina, Lourdes. (2003). La Gestión Participativa como eje impulsor del cambio en el proceso de innovación curricular de la Licenciatura en Turismo de la UAEM. (Tesis Doctoral). Universidad La Salle, México.

Morgan, Damian. (2002). Working Paper Series. Flexible Learning Practices In Tourism Courses. Recuperado de http://www.buseco.monash.edu.au/mgt/research/workingpapers/2002/wp29-02.pdf

Morgan, Michael. (2004). From production line to drama school: higher education for the future of tourism. International Journal of Contemporary Hospitality Management, 16. Recuperado http://www.emeraldinsight.com/journals.htm?articleid=867522\&show=abstract

Morin, Edgar. (1999). Los siete saberes necesarios para la educación del futuro. México: UNESCO.

Motta, Raúl. (2002). Complejidad, educación y transdisciplinariedad. Signos Universitarios: Revista de la Universidad del Salvador (37). Recuperado de http://dialnet.unirioja.es/servlet/articulo?codigo $=740991$ 
Najmanovich, Denise. (2001). La complejidad: De los paradigmas a las figuras del pensar. Revista Emergence. Presentado en el Primer Seminario Bienal de Implicaciones Filosóficas de las Ciencias de la Complejidad. Cuba: La Habana

Ocaña, Raymundo. (2010). Pasado y presente de la investigación educativa. Revista Digital Universitaria, 11(2). Recuperado de http://www.revista.unam.mx/vol.11/num2/art18/int18.htm

Olsson, Anders y Lofgren, María. (2007). Power and the tourism curriculum. $16^{\text {th }}$ Nordic Symposium in Tourism \& Hospitality Research. Helsingborg, Sweden. Recuperado de http://www.msm.lu.se/fileadmin/files/msm/bilder/Nordic16/Olsson and Martinsson Pow er and the tourism curriculum.pdf

Organización Mundial del Turismo - OMT. (2002). The Key Role Of Education in the New Age of Tourism: The WTO Education Council Takes On New Challenges. Boletín de Prensa de la Organización Mundial del Turismo. Recuperado de http://www.hospitalitynet.org/news/4012371.html

Pérez, Augusto. (2007). Gestión del conocimiento en la universidad. $4^{\circ}$ Encuentro Nacional y Latinoamericano: La Universidad como Objeto de Estudio. Recuperado de http://www.scielo.br/pdf/aval/v12n4/a03v12n4.pdf

Pérez, Miguel. (2000). Conocer el currículum para asesorar en centros. España: Aljibe.

Polo, Marina. (2011). Retos y Perspectiva de Innovación Curricular en Educación Superior. En Lourdes Medina y Laura Guzmán (comps.), Innovación Curricular en Instituciones de Educación Superior. Pautas y procesos para su diseño y gestión (Documentos, pp.17-28). México: ANUIES-COMINAIC.

Rogiers, Xavier. (2010). Una pedagogía de la integración. Competencias e integración de los conocimientos en la enseñanza. México: Fondo de Cultura Económica.

Rojas, Susan. (2003). La formación turística en la Educación Básica Chilena. Tesis de Licenciatura Escuela de Ingeniería Comercial, Facultad de Administración y Economía, Universidad Tecnológica Metropolitana. Santiago de Chile, Chile.

Stenhouse, Lawrence. (1991). Investigación y desarrollo del curriculum. En La pedagogía hoy ( $3^{\mathrm{a}}$ ed.). Madrid: Morata.

Tamayo, Leticia y Peñaloza, Laura. (2005). Investigación en Turismo y Educación en la Universidad Autónoma del Estado de México. Teoría y Praxis (1), 87-95. México: Universidad de Quintana Roo.

Tedesco, Juan Carlos. (1986). Los Paradigmas de la Investigación Educativa. Santiago: FLACSO. Recuperado de 2011 de www.metabase.net/docs/upn/14908.htm

Terigi, Flavia. (2002). Análisis Comparativo de los Currículos Iberoamericanos: Procesos, Condiciones y Tensiones que debemos considerar. IV Encuentro Internacional de 
Educación Inicial y Preescolar. La Habana, Cuba. Recuperado de 2011. http://www.oei.es/linea3/terigi.pdf

Torres, Rosa María. (2003). Procesos y Prácticas Curriculares. En Díaz Barriga, Ángel; (Coord.), La investigación curricular en México. La década de los noventa (pp. 165206). México: UNAM. Recuperado de 2011 de http://densev.gob.mx/biblioteca/modelo integral/Investigacion curricular en Mexico A Diaz Barriga.pdf

Tribe, John. (1997). The Indiscipline of Tourism. Annals of Tourism Research, 24(3). Recuperado de http://www.sciencedirect.com/science/article/pii/S0160738397000200

Tribe, John. (2001). Research paradigms and the tourism curriculum. Journal of Travel Research, 39(4). Recuperado de http://jtr.sagepub.com/content/39/4/442.short

Tribe, John. (2002). The Philosophic Practitioner. Annals of Tourism Research, 29(2). Recuperado de http://www.sciencedirect.com/science/article/

Tribe, John. (2003). Delivering Higher Quality: A Comparative Study of Lecturers' Perceptions and QAA Subject Review in Tourism. Journal of Hospitality, Leisure, Sport and Tourism Education, 2(1). Recuperado de http://www.heacademy.ac.uk/assets/documents/subjects/hlst/vol2no1 delivering high quality.pdf

Tribe, John. (2005a). Overview of Research, En David Airey and John Tribe (eds.), An International Handbook of Tourism Education (pp. 25-43). Oxford, Elsevier, Recuperado de http://www.lavoisier.fr/livre/notice.asp?id=OOSWOKAKXXLOWJ

Tribe, John. (2005b). Tourism, knowledge and the curriculum. En David Airey and John Tribe (eds.), An international Handbook of tourism Education. Oxford, England: Elsevier. http://www.lavoisier.fr/livre/notice.asp?id=OOSWOKAKXXLOWJ

Tribe, John and Airey, David. (2007). Developments in Tourism Research. Oxford: Elsevier

Urry, John. (2001) Mobility and proximity. Recuperado de http://www.ville-enmouvement.com/interventions/John Urry.pdf

Vera, José Fernando e Ivars, Josep Antoni. (2001). La formación y la investigación turística en España: una visión de síntesis. Papers de turismo, (29). Recuperado de http://dialnet.unirioja.es/servlet/articulo?codigo $=246257$

Wang, Jie. (2008). Is Tourism education meets the needs of the tourism industry? An Australian case study. (Tesis de Maestría en Turismo). Universidad de Canberra, Australia. Recuperado de http://www.canberra.edu.au/researchrepository/file/1d7eef386d47-552b-673e-adb17f0c721a/1/full text.pdf 